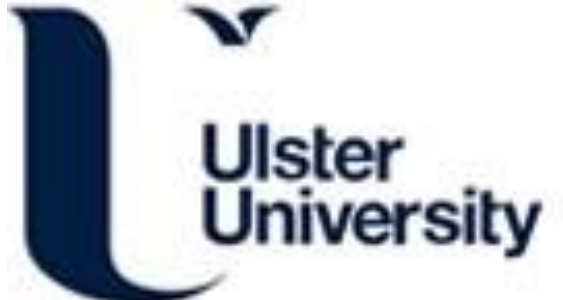

\section{Embedding creative Processes in the Development of Soft Body Armour: Physiological, Aesthetic, Functionality and Strategic Challenges}

Coulter, J. (2013). Embedding creative Processes in the Development of Soft Body Armour: Physiological, Aesthetic, Functionality and Strategic Challenges. In Innovation through Knowledge Transfer 2012 Series: Smart Innovation, Systems and Technologies, Vol. 18 (Vol. 2013, pp. 1-12). Springer. https://doi.org/10.1007/978-3642-34219-6_19

Link to publication record in Ulster University Research Portal

Published in:

Innovation through Knowledge Transfer 2012 Series: Smart Innovation, Systems and Technologies, Vol. 18

Publication Status:

Published (in print/issue): 01/01/2013

DOI:

10.1007/978-3-642-34219-6_19

\section{Document Version}

Author Accepted version

\section{General rights}

Copyright for the publications made accessible via Ulster University's Research Portal is retained by the author(s) and / or other copyright owners and it is a condition of accessing these publications that users recognise and abide by the legal requirements associated with these rights.

\section{Take down policy}

The Research Portal is Ulster University's institutional repository that provides access to Ulster's research outputs. Every effort has been made to ensure that content in the Research Portal does not infringe any person's rights, or applicable UK laws. If you discover content in the Research Portal that you believe breaches copyright or violates any law, please contact pure-support@ulster.ac.uk. 


\title{
Embedding creative Processes in the Development of Soft Body Armour: Physiological, Aesthetic, Functionality and Strategic Challenges
}

\author{
Janet Coulter \\ Research Institute for Art and Design (RIAD), University of Ulster, Belfast, UK
}

\begin{abstract}
The paper describes how creative processes were applied to developing a new product range, to enhance performance, streamline production, reduce costs and open up new markets for body armour solutions. It describes how a company with a proven track record in manufacturing, had lost market share during the first Gulf war due to supply chain issues and had found it difficult to regain share, as the market place had shifted in terms of design. The paper details internal and external challenges in bringing creative processes to the company, to enhance personal protection, improve performance and deliver on aesthetics. Social contexts and physiological issues brought additional challenges. From a business operations perspective, valuing and solving design problems had to be cost effective to manufacture using existing technology. The paper outlines how an academic in fashion and textiles used anthropometrics to research and develop creative solutions for soft body armour. The innovative, new products are now used by security forces globally.
\end{abstract}

Keywords: Design led, User-centred design, Anthropometrics, Innovation, Knowledge Management, Knowledge Exchange

\section{Introduction}

HE institutions in the UK contribute significantly to economic development and underpin a considerable portion of the knowledge economy. The creative industries are growing rapidly and are worth about $£ 0.5$ Billion to the Northern Ireland economy alone. The ability to use creativity to generate income has significant advantage within the knowledge economy and partnerships between higher education, government and industry can offer low risk, highly effective solutions in volatile, economic climates. 
The company partner is a manufacturer based in Northern Ireland, producing soft body armour solutions. At the commencement of the project, the company had a proven track record in manufacturing but had lost market share during the first Gulf war due to issues with the supply chain.

Having little design experience and found it difficult to regain market share and the key challenge facing the company was how to increase growth and profitability in a dynamic environment, where new competitors were entering the marketplace. It was within this context that a partnership was formed between the company and The University of Ulster.

Investigative research led to a review of the company's business strategy and its approach to design. An analysis and evaluation were presented to management, identifying several key objectives to be addressed through a knowledge transfer project (KTP). KTPs are government sponsored knowledge and technology transfer programmes that enable and support interaction between academia and industry to the benefit of both partners. The key objective is that knowledge and academic expertise is transferred to industry and 'know-how' and industrial expertise is transferred to academia through an industry-based project.

New business strategies were implemented, with design led innovation as the key competitive strength. An amalgamation of several strategies enabled the company to address its challenges from a design management perspective. The business aim was simple, to develop a sustainable business strategy that would regain market share and increase profitability, however the challenges were complex and required a multi-faceted approach. Two case studies are briefly overviewed to demonstrate how some goals were achieved.

\section{Rationale for the Research}

SMEs are facing strong competition globally and adaption to change provides the key to sustainability and continued success. An internal analysis carried out by the company prior to the project commencing, revealed that creativity and design had been neglected and having neither the internal resources, nor an understanding of design, they approached the University and a collaboration was formed to develop new products, to enable diversification into new markets. The company had managed to trade successfully with a basic product range but wanted to increase market share. Its products, which met all Ministry of Defence specifications, had not previously needed to have visual appeal but clients were now asking for more design alongside functionality, for example 'low-vis' solutions, when 'soft polic- 
ing' in communities was required and enhanced, 'high-vis' solutions for riot situations. With no design capability, the company did not understand how to value design or innovation. The primary challenge was to get the company to recognise, understand and value design and then guide it towards embedding design at the core of all its strategic decision-making.

Companies can often fail to see design as a strategic asset, however research shows that companies which embrace it, tend to be more successful in the market place (Cooper \& Press, 2000). Olins (1990) notes that companies must recognise design as a vital resource for it to become part of a management strategy and bringing effectively managed design on board can directly contribute to sustainable growth and commercial success.

The main issues were in relation to improving functionality of design, however aesthetical, physiological and social aspects needed to be considered. Every designed product provides human experiences (Press \& Cooper 2005) and consideration of human factors and user-centred design became pivotal in the product development. In applying creative processes several problems were identified and resolved in terms of ergonomics, anthropometrics and aesthetics. The project needed to be driven by in-depth knowledge of how textiles drape, move, react, and contour around a dynamic body, combined with an understanding of visual impact and functionality in clothing. With these factors in mind, it was determined that a fashion designer would offer the best skills set.

\section{Setting Objectives}

Knowledge management has become increasingly important to companies and Grant (1996) advises that knowledge integration is the primary purpose of any organisation and that knowledge transfer is a key mechanism for knowledge integration (Grant and Baden-Fuller, 1995). An internal review by the Academic revealed that the lack of design knowledge in the company was hampering current operations and this was likely to continue. The company's ad-hoc approach to design would no longer suffice and the review conclusions formed the objectives for the project. The company needed to:

- Streamline production

- Embed an in-house design ethos throughout the company

- Enhance product range to attract a more diverse customer base

- Create Product Data Management systems (PDMS) to manage knowledge and information 
- Invest in CAD and CAM systems to develop design efficiently

- Develop a 'Fabric Strategy' to aid Research \& Development of new products

\subsection{Streamline Production}

A key objective was to reduce manufacturing costs and streamline production. An analysis of productivity revealed that the company offered over 100 size variations of its product, which hampered output on the production line and such diversity was not sustainable or cost effective. Anthropometrics were used to undertake a nationwide sizing exercise, measuring forces across the UK, including Group 4 Securicor and Devon and Cornwall Police. The data was analysed and applied to advanced pattern engineering techniques, resulting in a reduction of sizing options by over $50 \%$ from 100 to 45 sizes. The exercise was significant as it demonstrated to the company that there were tangible benefits to employing innovative, design techniques. An additional benefit was that excellent relationships and personal service with the existing customer base was maintained.

\subsubsection{Embedding Design: A company wide design ethos}

Embedding design throughout the company required a complete culture shift. Von Stamm (2008) cautions that innovation alone is not sufficient contending that the behaviours of people in the organisation need to change. She suggests a 'people based' approach to ensure successful outcomes and advocates the formation of an innovation team, when innovation requires a different culture and mindset from routine business. This framework was adopted for the project, to realise quick results, which could then be rolled out into the company over a longer period of time.

The organisation had to commit to making changes in its approaches and processes, to ensure the investment in design paid off. Jenkins (2010) describes how organisations are often antagonistic to design, suggesting that existing behaviours and engrained attitudes can potentially 'squeeze the life out of design' unless addressed. Concurring with Von Stamm, he recommends an entire cultural transformation, concluding that having a designmchampion could be a significant catalyst for cultural change. The KTP Associate (the designer) acted as a conduit to integrate a companywide approach to design, embedding value and expertise to achieve innovative, new products. Thakara (1997) acknowledges that innovation is a major contributor to the ongoing success of any enterprise. 
The project initiated the implementation of a design strategy at all levels, as identified by Kelley (2004) and Johnston (2003). Hands (2009) contends that developing design expertise may be especially critical for competitive and growth purposes within global markets; however he acknowl5 edges that it is only part of the picture and design needs to be carefully managed in line with the company's overall strategy. Cooper and Press (2000) concur and recommend blending design with effective management to ensure successful implementation of innovative new products, concluding that fostering creativity should be a specific management goal.

\subsubsection{Embedding Design: New product development}

Innovative design is pivotal to creating new opportunities, nurturing interdisciplinarity and leading to new collaborations, which allow for a holistic approach to radical new product development. The company needed to increase its competitiveness and this would best be achieved through product innovation and diversification into new markets. It can be financially risky to diversify both product and market simultaneously, but at the time this strategy was deemed necessary. Companies can gain competitive advantage during recession through innovative approaches to product development, whilst entering new markets, however they need to be able to increase both efficiency and innovation during a downturn (Geroski and Gregg, 1994 and 1997).

Rhodes and Slater (2009) argue that turbulent times bring with them opportunities as well as threats, a view supported by Deans et al. (2009). The recession had led to several changes in key personnel in the company and its priority needed to be adapting quickly to new challenges. Hartman (2009) suggests that flexibility and rapid response to changing conditions are key objectives during periods of uncertainty. Radical innovation in the company's business model, as described by Leifier et al (2000) was necessary to harness future success. Most new products favour lower-risk incremental innovation, as radical innovation may bring further uncertain dimensions of new technologies and new markets (McDermott and Colarelli O'Connor, 2002); however fundamental changes in approaches to new markets and products were vital for the company's economic survival.

New markets were investigated, including paramedics and with these came added design challenges. Research at the time showed that knife crime had increased significantly, rising by $26.9 \%$ between 2006-2007 [1], with frontline health workers being most at risk of close range stabbings. In 2007 there were 1006 physical assaults against ambulance staff in England [1] and many Health authorities continue to report increasing attacks on frontline staff (East of England Ambulance Service reporting a 10\% in- 
crease in assaults and South Central, reporting a rise of 22\% in 2010-11) [2]. This statistical evidence inspired the development of new products to meet the needs of paramedics, such as anti-stab vests, which resist knife penetration in a way that bullet proof vests do not, with high flip collars to counter neck stabbings and attacks from behind. Innovative, user-centred design features were developed such as heat management, back support and systems-orientated designs to ensure compatibility with other on-thejob equipment. Other new product innovations included a 'quick release' system to allow the wearer to swiftly remove armour and themselves from high-risk situations, thus increasing speed and mobility, for example from a burning vehicle, or if the wearer fell into water and needed to off load weight to prevent drowning. Quick release systems also allow medics to attend injured soldiers more easily in the field. This design has continued to be improved in close co-operation with special forces units deployed in conflict zones in Iraq and Afghanistan.

\subsubsection{Embedding Design: External considerations}

The company needed its new core values in design to be communicated effectively to its customers and had in its favour its brand name. The company was based in Northern Ireland, whose political history has led it to be associated with high quality, body armour; the 'Northern Ireland' symbolism provided customer confidence and a badge of assurance. However, the new products needed to deliver on performance and create additional value to the core function of protection. Value innovation is based on a deep understanding of the organisation's culture and potential and the needs and desires of the end-users (Fraser, 2010). It is widely accepted that 'value' is a key determinant of customer loyalty and Parasuraman and Grewal (2000) note the impact of technology on the relationships between quality, value and customer loyalty. The project utilised a range of creativity tools, to define the current relationship that the company had with its customers and used the data to project the relationship that it desired to have with its customers. The differences between the two datasets, known as the 'Innovation Gap' (Estrin, 2009) were analysed and the results used as a tool for closing the gap to enhance customer loyalty. Mellis (2003) contends that involving customers in the innovation process leads to true partnership, maximising the value to all parties. The company's strong relationship with its customers, led to a bespoke service, accommodating special requests, such as customised vests for officers returning to work after illness, with a colostomy bag or after a mastectomy. 


\subsubsection{Embedding Design: Internal considerations}

The company's ad-hoc approach to design had meant that decisions were often reactive and extemporised, resulting in acquired knowledge, which was disjointed and difficult to quantify, as the company struggled to determine the intrinsic value of it. This had allowed pockets of 'informal power' to build up. There was some resistance to the ideas of change that the KTP project was proposing, with a perception that this might displace the 'power base'. Resistance to change, first observed by Lewin (1947) is common in organisations (Dent and Galloway Golden, 1999). This posed an unforeseen challenge to the project, which needed to be addressed.

Cohen et al (1990), argue that an organisation's 'absorptive capacity' (The ability to recognise the value of new external information and apply it to a business model) depends on individuals and their co-operation on transfers of knowledge across boundaries and sub-units within a company. They continue that 'gatekeepers' (in this instance the KTP Associate) can facilitate the transfer of knowledge across boundaries to increase reception of new ideas, particularly in turbulent environments. Existing company structures needed to be addressed; resistance to change had to be overcome, design needed to be valued and shared between departments and strategies to survive the recession implemented. The introduction of an inhouse design capability provided new focus and 'buy in' was eventually achieved by involving all departments: technical, quality control, purchasing, shop floor and senior management, facilitating and embedding design at the core of strategic decision-making. All parties worked closely throughout these challenges, with successful outcomes.

Esslinger (2009) stresses that all stakeholders need to understand the fundamental role of creativity in strategic business approaches and presents a useful, three-step, strategic framework comprising: groundwork, creative collaborations and marketing. This strategic framework was applied to the project. As the team gelled, creative collaborations developed and the term 'knowledge transfer' no longer accurately described the project. It became a journey of 'innovation transfer' and 'knowledge exchange'; combining the company's significant expertise in ballistics, with the Academic's and Associate's design knowledge. The process of design was neither linear, nor one-way. It became a two-way process, with a significant culture shift as the change agent. The knowledge acquired was through a shared experience as trust in the partnership was established. 


\section{CAD based systems to manage of the design process}

Prior to the project, designs were hand drawn making modifications slow and open to error. Additionally, there was no effective mechanism for managing technical patterns. Lack of communication between departments left product information difficult to control. A product data management (PDM) system was introduced to manage the life cycle of the each product. The PDM was held centrally and could be accessed and tracked by all departments, ensuring transparency, accuracy of information and better workflow processes. New 'Windows' based software for technical pattern management was introduced to create and modify patterns efficiently, enabling the design team to manipulate them to optimise material utilization and reduce material costs. New design software meant designs were produced more efficiently, were visually more attractive to potential new clients and easily understood by pattern cutters. Presentation improved dramatically and this enriched marketing capabilities.

Towards the end of the project, new investors bought over the company and recognising the potential of CAD/CAM based systems, made substantial investment into an automated cutting system to augment speed and precision in production. All four CAD systems were compatible with each other and their integration gave greater control, management and efficiency over the entire design and production process.

\section{Smart Fabrics Strategy}

Body armour enables humans to function in extreme environments, however it limits heat transfer, impeding activity and performance due to the increased weight and poor moisture management properties. Performance textiles have a high potential for payoff in the fight against terrorism (Jayaraman et al 2005). Improving the textile properties of the vests, alongside ergonomics contributed to overall, enhanced performance. Loose fitting garments allow for better heat transfer (Daanen et al, 2006), but body armour must be close fitting to be functional. A fashion designer's knowledge was critical to the project, as it brought understanding of how materials could be effectively combined to add competitive advantage.

The designer was also able to establish trusted relationships with specialist suppliers and build a performance-fabrics database to augment product development. Atkinson (2003) stresses the importance of building relationships with supply chains to promote innovation in a company. Many suppliers are experts in their field and collaboration early on in the design 
process can contribute to the finished design and enhance competitive advantage, reducing costs, before they are built into a specification.

\section{Research and development}

Research and development feeds design with new technologies, materials and processes (Cooper and Press 2009) and provides a focus and strategic direction. R\&D gave rise to two additional research opportunities during the project and although specific details of findings are outside the scope of this paper, the projects have been overviewed.

\subsection{Case Study 1: Moisture Management}

Investigative research was undertaken to determine if innovative design and performance fabrics could be engineered to improve moisture management, potentially reducing the associated physiological effects. Armoured vests have up to fifteen layers of laminated Kevlar sealed inside a polyurethane cover, causing poor wicking properties. This combined with high external temperatures and/or stressful situations causes the wearer to perspire heavily, potentially leading to dehydration and disorientation, reduced judgment and cognitive performance abilities (Gopinathan, 1988). A six week study at the University of Ulster (Coulter et al 2009), using live subjects and an acclimatisation chamber, tested six prototyped armoured vests using a number controls and variables. Robust statistical applications to the dataset were used to determine the best combination of design and performance fabric. The results were then made available to the company.

\subsection{Case Study 2: Moulded Thermoplastic composites for female body contouring}

Stitching darts into multiple layers of Kevlar meant that 30 darts were required to shape each female armoured vest. This labour intensive process gave crude results, reducing aesthetic appeal and functionality. The author's research investigated whether multiple layers of Kevlar could be moulded, three dimensionally over a double curvature in one operation to enhance the ergonomic shape for females. A collaborative experiment between Engineering and Textiles Fashion at the University (Coulter and Archer 2009) was initiated to determine if it was possible to design and 
manufacture a 3 dimensional multi-layer Kevlar component, using thermoplastics. A body scanner was used to obtain accurate data on female anatomy. This data was used to successfully mould multi-layers or Kevlar onto a female torso shape in one operation, using thermoplastic techniques. The findings were presented to the company.

\section{Conclusions}

The overall project met with many diverse and unforeseen challenges, which spanned management, communication, technology, production and design. The issues were complex, however through creative approaches, all main KTP objectives were met and challenges largely overcome. The project demonstrates how knowledge exchange has superseded knowledge transfer and how this two-way process can be a rich resource for both universities and industry.

Considerable design and creative knowledge was transferred to the Company, allowing design to be embedded and placed at the core of strategic decision-making. Additional new knowledge was created through interdisciplinary, collaborative research, which facilitated the Company in gaining competitive, commercial advantage. Significantly the outcomes of the project show how design knowledge can contribute to economic growth and demonstrates how important innovation is to the creative industries and the changing economy. The success of the project can be measured through its outcomes. Contracts with many new customers such as: G4S, Devon and Cornwall Police, Gwent Police, Italian Air Force, Trinidad and Tobago Police and Belfast City Council were secured. Additionally a NATO contract, the biggest in the company's history was secured, with a first order placed for 6000 vests. The company continues to trade successfully and uses its design expertise to bring innovative new products to new markets, with recent examples including protection vests for the media in war zones, de-mining suits for aid workers and casual wear with covert, anti-slash protection built in.

\section{References}

Atkinson D (2003) Supply Chains: Collaborate to Innovate. In: Jolly A (ed) Innovation; Harnessing Creativity for Business Growth. Kogan Page, London

Cohen W, Levinthal, D, Damiel A (1990) Absorptive Capacity: A New Perspective on Learning and Innovation, ASQ, 35, (1990), 128-152, faculty.babson.edu/krollag/org_site/org.../cohen_abcap.htm. (last accessed 10 January 2012) 
Cooper R, Press M (2000) The Design Agenda; A guide to Successful Design Management. John

Wiley \& Sons, UK

Coulter J, Davison G, McCLean C, Carmody O (2009) 'What if?' Research and Innovation by Design. Proceedings of The Senior Staff Conference, University of Ulster

Coulter J. Archer E (2009) “'What if?' Research and Innovation by Design. Proceedings of The Senior Staff Conference, University of Ulster

Daanen H A M, Reffeltrath P A, Koerhuis C L, (2000) Ergonomics of Protective Clothing. In The Netherlands in Intelligent Textiles for Personal Protection and Safety. Jayaraman S et al. (Eds.). IOS Press, Amsterdam

Deans G, Kansal C, Mehltretter S (2009) 'Making a Key Decision in a Downturn: Go on the Offensive or be Defensive?'. Ivey Business Journal Online, Jan/Feb.

Dent E B, Galloway Goldberg S (1999) Challenging "Resistance to Change". Journal of Applied Behavioural Science; 35; 25 DOI: 10.1177/0021886399351003

Esslinger H (2009) A fine Line: How business strategies are shaping the future of business. John Wiley \& Sons, San Francisco

Estrin J (2009) Closing the Innovation Gap: Reigniting the Spark of Creativity in a Global Economy. Mc-Graw Hill

Fraser H (2010) Design Business: New Models for Success. In Lockwood, T (ed) Design Thinking. Allworth Press

Geroski P A, Gregg P (1994) Corporate Restructuring in the UK during the Recession. Business Strategy Review, 5, 2, 1-19

Geroski P A and Gregg P (1997) Coping with Recession: UK Company Performance in Adversity.

University Press, Cambridge

Gopinathan P M, Pichan G, Sharma V M (1988) Role of dehydration in heat stress-induced variations in mental performance. Arch Environ Health $43: 15-17$

Grant R M (1996) Prospering in dynamically competitive environments, Organisational capability as knowledge integration. Organisation Science Vol. 7 No.4, pp. 375-87

Grant R, Baden-Fuller C (1995) A knowledge-based theory of inter-firm collaboration. Academy of Management Best paper proceedings pp.17-21

Hartman N (2009) Sure ways to tackle uncertainty in tough times. Financial Times, Managing in a Downturn Series, February 5. http://www.ft.com/reports/managingdownturn. (Last accessed 1512 2011)

Jayaraman S, Kiekens P, Grancaric A M (2006) Heat Strain and Fit, TNO Defense, Security \& Safety, The Netherlands in Intelligent Textiles for Personal Protection and Safety. Jayaraman S et al. (Eds.). IOS Press, Amsterdam

Jenkins J (2010) Creating the right environment for Design. In Lockwood T (ed) Design Thinking. Allworth Press

Johnston R E (2003) The power of Strategy Innovation; A new way of linking creativity and strategic planning to discover great business opportunities. Amacom

Jolly A (2003) Innovation: Harnessing Creativity for Business Growth. Kogan Page, London

Kelley T, Littman J (2004) The Ten Faces of Innovation; Strategies for heightening Creativity. Profile Books

Kitching J, Blackburn R, Smallbone D, Dixon S (2009) Business Strategies and Performance during difficult economic times. Department of Business Innovation and Skills. Small Business Research Centre, Kingston University, 2010-01-04

Kotter J P (1995) Leading Change: Why Transformation efforts fail. Harvard Business Review, 73 (2), 59-67

Leifer R, McDermott C M, Colarelli O'Connor G, Peters L S, Rice M P, Veryzer R W (2000) Radical Innovation: How Mature Companies Can Outsmart Upstarts. Harvard Business School Press, Boston

Lewin K (1947) Frontiers in Group Dynamics. I. Concept method and reality in social sciences: social equilibria and social change. Human Relations, 1, 5-41 
Lieberman H R (2007) Hydration and Cognition: A Critical Review and Recommendations for Future Research. J Am Coll Nutr October, vol. 26 no. suppl 5 555S-561S

Lorange P (2009) Optimists have a bright future. Financial Times, Managing in a Downturn Series, January 29, online at: http://www.ft.com/reports/managingdownturn. (Last accessed 1412 2011)

McDermott C M, Colorelli O'Connor C (2002) Managing radical innovation: an overview of emergent strategy issues. Journal of Product Innovation Management Volume 19, Issue 6, pages 424-438, November

Mellis W (2003) Partnering with Customers. In: Jolly A (ed) Innovation; Harnessing Creativity for Business Growth. Kogan Page, London

Olins W (1990) The Wolff Olins guide to corporate identity. The Design Council, London 12

Parasuraman D, Grewal D (2009) The impact of technology on the Quality-Value-Loyalty-Chain, A research Agenda. Journal of The Academy of Marketing Science, Volume 28, No.1, pages 168-174

Press M, Cooper R (2005) The Design Experience, The Role of Design and Designers in the Twenty First Century. Ashgate Publishing Limited, Hampshire, England

Rixon D (2003) Strategic Commitment- The Foundation Stone for Innovation. In: Jolly A (ed) Innovation;

Harnessing Creativity for Business Growth. Kogan Page, London

Thakara J (1997) Winners! How today's successful Companies innovate by Design. Gower, London

Rhodes D, Slater D (2009) Seize Advantage in a Downturn. Harvard Business Review, 87, 2, 50-58.

Vinding A L (2004) Human Resources; Absorptive Capacity and Innovative Performance. Research on Technological Innovation and Management Policy, Vol. 8, p. 155-178

Von Stamm B (2008) Managing Innovation, Design and Creativity; 2nd edition. John Wiley and Sons ltd, Chichester

[1] http://www.ppss-group.com/blog/when-will-ambulance-staff-and-paramedics-be-issued-with bodyarmour/ (last accessed 1512 2011)

[2] http://news.bbc.co.uk/1/hi/uk/7088341.stm (last accessed 1512 2011)

Acknowledgements:

Mr. Gary Hayes - Sales Director, at Global Armour Ltd, Lisburn, UK (KTP Company supervisor)

Mrs Orlagh Carmody - Head of Design at Global Armour, Lisburn, UK (KTP Associate)

Dr. Edward Archer, Research Fellow. Engineering Research Institute, University of Ulster

Dr. Gareth Davison, Senior Lecturer in Sport and Exercise, University of Ulster 